\title{
Investigação Prospectiva do Novo Coronavírus e de Fármacos Antivirais com Potencial Atividade Terapêutica para o Tratamento de Pacientes Infectados pela COVID-19
}

\author{
Prospective Investigation of the New Coronavirus and Antiviral Drugs \\ with Potential Therapeutic Activity for the Treatment of Infected Patients \\ by COVID-19
}

\author{
Williams Raphael de Souza Morais ${ }^{1}$ \\ Nathalia Marcelino Pereira Queiroz ${ }^{1}$ \\ Jaceguai Soares da Silva ${ }^{2}$ \\ Adriana Santos Ribeiro ${ }^{1}$ \\ Josealdo Tonholo ${ }^{1}$ \\ ${ }^{1}$ Universidade Federal de Alagoas, Maceió, AL, Brasil \\ ${ }^{2}$ Instituto Federal de Educação, Ciência e Tecnologia do Amapá, Laranjal do Jari, AP, Brasil
}

\begin{abstract}
Resumo
A pandemia de COVID-19, causada pelo novo Coronavírus, encontrado em dezembro de 2019 em Wuhan, na China, havia atingido 754.498 pessoas e causado a morte de 36.571 pessoas em todo o mundo até o dia 31 de março de 2020. O sistema de saúde mundial entrou em crise e um dos grandes gargalos é o tratamento dos pacientes infectados. Com o objetivo de fazer um mapeamento científico e tecnológico acerca desse novo vírus e de fármacos antivirais com potenciais atividades terapêuticas no tratamento da COVID-19, foram realizadas buscas $e$ análises de artigos científicos e patentes em bases de dados nacionais e internacionais. Foram recuperadas 2.977 patentes (Orbit) e 14.056 artigos (Scopus) sobre Coronavírus e 296 artigos (Scopus) especificamente sobre o novo Coronavírus, predominantemente da China. Foram identificados mais de 20 fármacos antivirais em avaliação em diversas partes do mundo. $\mathrm{O}$ trabalho aponta para a potencialidade de uso de fármacos já existentes no tratamento à doença, a exemplo de Cloroquina, Hidroxicloroquina, Ritonavir, Lopinavir, Remdesivir e Ribavirin.
\end{abstract}

Palavras-chave: Coronavírus. COVID-19. Tratamento. Fármacos.

\begin{abstract}
The COVID-19 pandemy, caused by a new coronavirus found in December 2019 in Wuhan, China, has infected 754,498 people and promoted the death of 36,571 people worldwide until March 31, 2020. Almost all the countries experimented collapses in them health system to take care of their population. This paper is devoted to show a scientific and technological mapping about this new virus and antiviral drugs with potential therapeutic activities in the treatment of COVID-19, it was performed by analysis of scientific papers and patents from Brazilian and international databases. 2,977 patents (Orbit) and 14,056 articles (Scopus) were found about coronavirus and 296 articles (Scopus) specifically about the new coronavirus, predominantly from China. More than 20 antiviral drugs were identified and are under evaluation in different parts of the world. The results also brings some news about the actual potential of use of some drugs like chloroquine, hydroxychloroquine, Ritonavir, Lopinavir, Remdesivir and Ribavirin.
\end{abstract}

Keywords: Coronavirus. COVID-19. Treatment. Drugs.

Área Tecnológica: Prospecção. Fármacos. Saúde. 


\section{Introdução}

Os coronavírus são vírus de RNA de fita simples positiva, envelopados, que podem infectar várias espécies, incluindo humanos, outros mamíferos e pássaros. Após a infecção, o indivíduo infectado pode desenvolver doenças respiratórias, intestinais, hepáticas e neurológicas (WEISS; LEIBOWITZ, 2011; CUI; LI; SHI, 2019). Os coronavírus são membros da ordem Nidovirales e da subfamília Orthocoronavirinae (WOO et al., 2012).

Em dezembro de 2019, o sétimo coronavírus humano, denominado "2019 novo coronavírus" (2019-nCoV) ou "Coronavírus 2 da Síndrome Respiratória Aguda Grave" (SARS-CoV-2), foi encontrado em Wuhan, na China. Em 31 de março de 2020, o número total de infecções e mortes por 2019-nCoV no mundo era de 754.948 e 36.571, respectivamente, de acordo com a Organização Mundial da Saúde (OMS) (HAN et al., 2020; WHO, 2020).

Os sintomas clínicos apresentados pela maioria dos pacientes foram tosse seca, dispneia $e$ febre. Essa epidemia é o terceiro surto de Coronavírus nos últimos 20 anos após a Síndrome Respiratória Aguda Grave (SARS-CoV) e a Síndrome Respiratória do Oriente Médio (MERS-CoV), gerando a doença mais conhecida por COVID-19 (Corona Virus Desease, year 2019). Embora a taxa de infecção seja significativa, estima-se a taxa de letalidade entre os casos confirmados de COVID-19 em 3,7\%, sendo os idosos (acima de 80 anos de idade), pessoas com múltiplas comorbidades e a população imunocomprometida, os pacientes com maior ocorrência de óbitos (KHACHFE et al., 2020).

A aplicação e a execução de medidas estritas de detecção, prevenção e controle têm a capacidade de limitar e de controlar a transmissão local. Entre as medidas a serem tomadas incluem-se: identificação rápida e maior vigilância de casos suspeitos, além de transferência $e$ isolamento de pacientes, diagnóstico rápido, rastreamento e acompanhamento de contatos em potencial. Cabe ressaltar que a adoção de um amplo conjunto de intervenções técnicas $e$ de operacionais depende do público de cada país, das infraestruturas e de recursos sanitários e laboratoriais (GILBERT et al., 2020).

Com a rápida disseminação do novo Coronavírus no mundo, o sistema de saúde mundial entrou em crise por causa do grande número de contaminados em um pequeno intervalo de tempo. O grande desafio está no tratamento dos pacientes infectados, pois ainda não existe um protocolo de medicamento.

Nesse intuito, este trabalho de pesquisa realizou uma investigação prospectiva, de cunho científico e tecnológico, a respeito do novo Coronavírus e de fármacos antivirais apontados como possíveis tratamento em pacientes infectados pela COVID-19.

\section{Metodologia}

As buscas foram efetuadas em bases de natureza tecnológica e em bases de produção científica, a fim de indicar os fármacos antivirais com possível ação terapêutica para o tratamento de pacientes acometidos pela COVID-19, a partir dos dados obtidos em artigos e em patentes. Os levantamentos foram realizados no dia 30 de março de 2020. 
Para realizar o mapeamento científico, foram utilizados como fontes os bancos de dados das bases Science Direct, Web of Science, Scopus e Scielo (somente Brasil); para o levantamento tecnológico, foram utilizadas as bases do Escritório Europeu de Patentes (Espacenet), do Derwent Innovations Index (DERWENT), da Thomson Reuters Scientifc, e o software Questel Orbit Intelligence ${ }^{\circledR}$, bases internacionais de patentes; a base do Instituto Nacional da Propriedade Industrial (INPI) também foi utilizada. Os acessos foram realizados por meio do Portal de Periódicos da Coordenação de Aperfeiçoamento de Pessoal de Nível Superior (CAPES), no canal de acesso da Comunidade Acadêmica Federada (CAFe). O acesso ao Orbit se deu devido à cortesia da Questel ${ }^{\circledR}$ em disponibilizar ao PROFNIT/FORTEC.

Os descritores utilizados para as buscas no presente trabalho são apresentados no Quadro 1 com a especificação dos termos utilizados em português, para as buscas na base de patentes do INPI, e os termos em inglês utilizados para as buscas nas demais bases de patente e bases de artigos.

Quadro 1 - Descritores utilizados nas buscas das diversas bases de patente e de artigos

\begin{tabular}{|c|c|}
\hline \multicolumn{1}{|c|}{ INPI } & DESCRITORES UTILIzADOs \\
\hline coronavirus & Bases de patentes e de dados internacionais \\
\hline coronavirus AND COVID-19 & coronavirus OR "corona virus" \\
\hline $\begin{array}{c}\text { coronavirus AND } \\
\text { COVID-19 AND farmac* }\end{array}$ & $\begin{array}{c}\text { (coronavirus OR "corona virus") AND ("COVID-19" OR "2019-nCoV") } \\
\text { (2019-nCoV") AND (pharmaceutic* OR drug*) }\end{array}$ \\
\hline
\end{tabular}

Fonte: Elaborado pelos autores deste artigo (2020)

Os operadores booleanos "and" e "or" foram utilizados para a limitação das buscas aos termos inseridos conjuntamente e para inclusão dos termos equivalentes, respectivamente. O operador coringa "*” foi usado para a recuperação de resultados com as possíveis variações do termo pesquisado. Todas as buscas foram realizadas no campo de pesquisa avançada, com a seleção da opção de busca no título e no resumo.

\section{Resultados}

O quantitativo de patentes com pedidos de depósito via Tratado de Cooperação em Matéria de Patentes (PCT) e de artigos científicos, recuperados por meio de combinações dos descritores especificados na metodologia, está exposto na Tabela 1.

Nas bases de dados científicas utilizadas, foi recuperado um grande volume de artigos, quando inserido o termo "coronavirus", mas quando combinado com o termo COVID-19, esse quantitativo foi reduzido em torno de $90 \%$, exceto na Scielo, base na qual nenhum artigo foi recuperado; quando combinados os termos "coronavirus, COVID-19 e fármacos", poucos artigos foram recuperados e nenhum documento de patente, conforme o terceiro conjunto de descritores dispostos no Quadro 1. 
Tabela 1 - Resultados das buscas nas bases Science Direct, SciELO, Scopus, Espacenet, Derwent, Questel Orbit e INPI

\begin{tabular}{|c|c|c|c|c|c|c|c|c|}
\hline DESCRITORES & $\begin{array}{c}\text { SCIENCE } \\
\text { DiRECT }\end{array}$ & $\begin{array}{c}\text { ScIElo } \\
\text { (BRASIL) }\end{array}$ & $\begin{array}{l}\text { WEB OF } \\
\text { SCIENCE }\end{array}$ & Scopus & EsPaCENT & DeRWENT & ORBIT & INPI \\
\hline $\begin{array}{l}\text { coronavirus OR } \\
\text { "corona virus" }\end{array}$ & 2247 & 4934 & 9370 & 14056 & 680 & 2625 & 2977 & 13 \\
\hline $\begin{array}{c}\text { (coronavirus OR } \\
\text { "corona virus") AND } \\
\text { ("COVID-19" OR } \\
\text { "2019-nCoV") }\end{array}$ & 149 & 0 & 96 & 296 & 0 & 0 & 1 & 0 \\
\hline $\begin{array}{c}\text { (coronavirus OR } \\
\text { "corona virus") AND } \\
\text { ("COVID-19" OR } \\
\text { "2019-nCoV") AND } \\
\text { (pharmaceutic* } \\
\text { OR drug*) }\end{array}$ & 23 & 0 & 4 & 21 & 0 & 0 & 0 & 0 \\
\hline
\end{tabular}

Fonte: Elaborada pelos autores deste artigo (2020)

No Scopus foram recuperados 14.056 artigos, esse dado revela que há um interesse científico acerca do tema "coronavírus". Os primeiros artigos datam de 1951, e, desde essa data, o volume de publicações tem crescido, como pode ser observado na Figura 1. Porém, a partir do ano de 2003 houve um elevado aumento de artigos publicados, provavelmente provocado pelo surgimento da infecção humana por meio do Coronavírus da Síndrome Respiratória Aguda Grave (SARS-CoV) na China, em 2002, e, posteriormente, o Coronavírus da Síndrome Respiratória do Oriente Médio (MERS-CoV) na Arábia Saudita, em 2012 (WHO, 2020), e, mais recentemente, a COVID-19 (ZHU et al., 2020), em dezembro de 2019. Isso resultou um número de publicação de 507 artigos, apenas no primeiro trimestre de 2020, demonstrando que há um grande interesse pelo tema. Esses três momentos estão destacados no gráfico da Figura 1.

Figura 1 - Quantidade de artigos científicos publicados por ano relacionados ao descritor "coronavírus" recuperados pela busca na base de dados Scopus

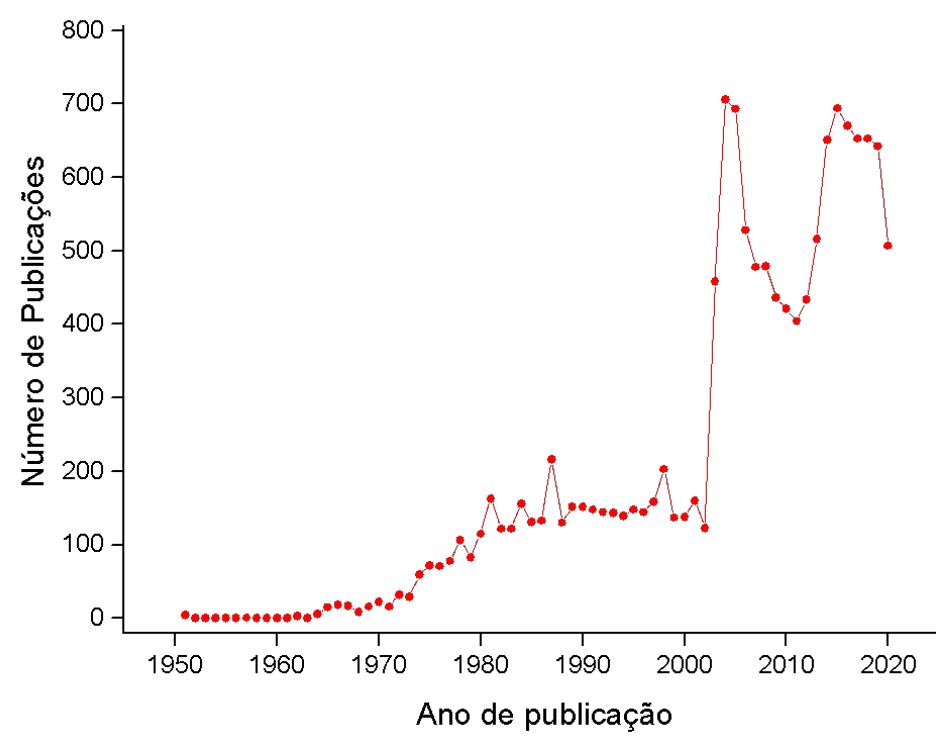

Fonte: Elaborada pelos autores deste artigo (2020) 
Nas bases tecnológicas, vários documentos de patentes foram recuperados quando inserido o descritor "coronavirus". Entretanto, quando utilizado a segunda combinação dos termos, "coronavirus" e "COVID-19", apenas um documento foi recuperado no Questel Orbit (Tabela 1). Esse resultado justifica-se pela recente descoberta da doença, em dezembro de 2019, significando que possíveis patentes depositadas até o presente momento estão no período de proteção legal de 18 meses, portanto, não disponíveis ainda publicamente nas plataformas de buscas.

Ainda considerando o software do Questel Orbit, foram recuperados um total de 2.977 documentos de patentes quando utilizado o descritor "coronavirus" no campo de busca. Na Figura 2 está descrito o número de depósitos de patentes nos últimos 20 anos, no qual pode-se perceber dois momentos de um grande número de depósitos: o primeiro foi entre os anos de 2003 e 2005, referente ao surgimento da infecção humana pela SARS-CoV, no Sul da China, em novembro de 2002 (DROSTEN et al., 2003, KSIAZEK et al., 2003); o segundo ocorreu no período entre 2013 a 2018, que se relaciona a uma contaminação de um outro CoV, o MERS-CoV, que surgiu na Arábia Saudita, em setembro de 2012. A mesma tendência de crescimento relacionada ao surgimento da SARS-CoV e da MERS-CoV observada para a publicação de artigos científicos ao longo dos anos, conforme discutido anteriormente.

Figura 2 - Quantidade de patentes depositadas nos últimos 20 anos relacionadas ao descritor "coronavírus", recuperadas pela busca no Questel Orbit

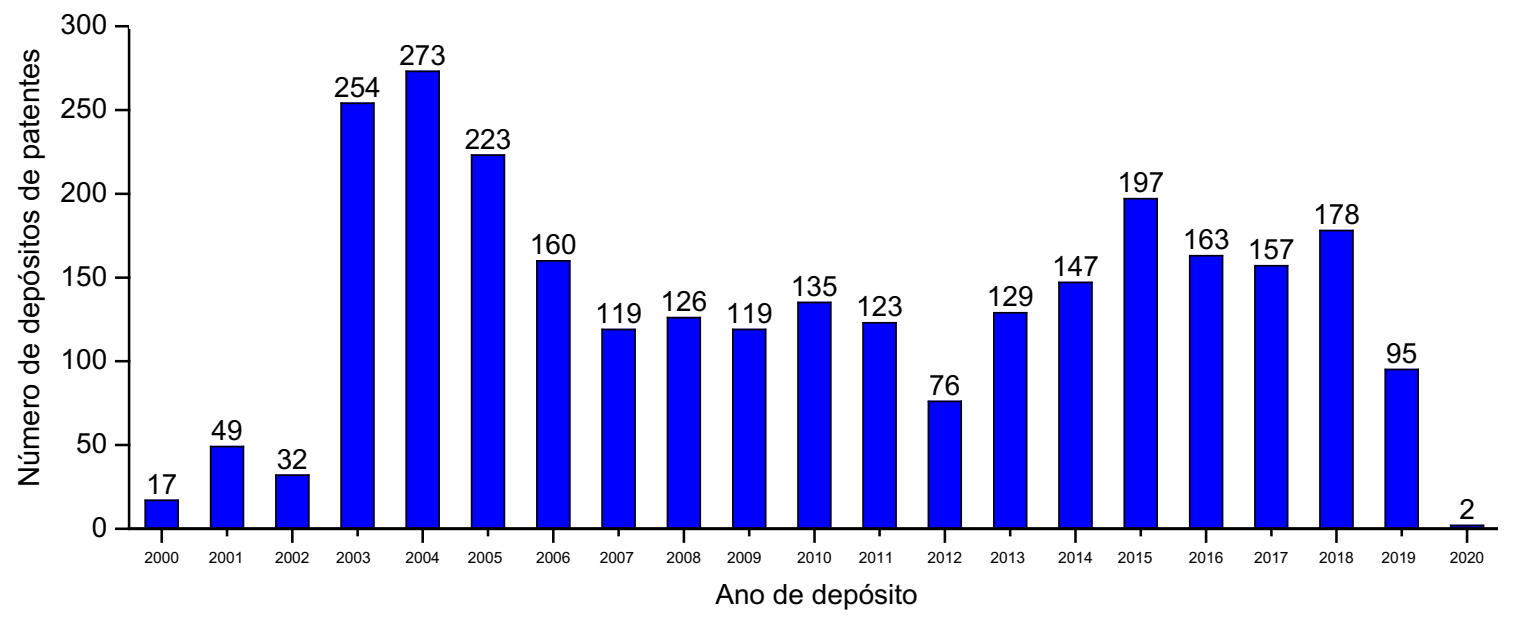

Fonte: Elaborada pelos autores deste artigo (2020)

Dos dois documentos de patentes do ano de 2020, mostrado na Figura 2, apenas um refere-se ao novo CoV. O documento da patente denominada Prescription for treating pneumonia infected by novel coronavirus and application thereof (CN110870402) trata-se de um preparado a partir da mistura, em diferentes proporções, de efedrina (Figura 3), um alcaloide simpatomimético derivado de plantas do gênero Ephedra (FOSTER; TYLER, 1999), que é um agente vasopressor, comumente usado para fins na prática anestésica (UNLUGENC et al., 2015) e em vários outros insumos utilizados na medicina chinesa tradicional para o tratamento de pacientes com doenças respiratórias. 
Figura 3 - Estrutura molecular da Efedrina

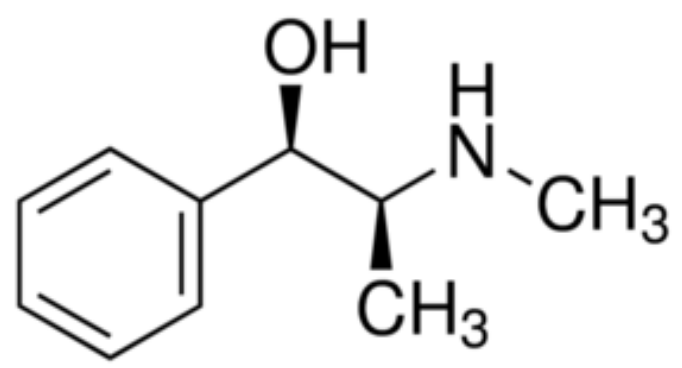

Fonte: Sigma-Aldrich (2020)

Na base do INPI foram recuperados 13 documentos de patentes relacionadas ao Coronavírus, porém nenhum deles tratava-se da COVID-19, já devidamente justificado pelo período de sigilo, isso foi constatado ao combinar os termos "Coronavirus" e "COVID-19", como descrito na Tabela 1, como resultado nenhum documento foi recuperado. Vale ressaltar que os documentos recuperados na primeira pesquisa estavam relacionados aos Coronavírus SARS-CoV e o MERS-CoV, dos 13 documentos, oito deles possuíam código IPC A61, que se refere à Ciência Médica ou Veterinária e Higiene.

Em relação ao segundo grupo de descritores, (coronavirus OR "corona virus") AND ("COVID-19” OR "2019-nCoV”), dos 96 artigos recuperados na Web of Science, apenas um é do ano de 2019, os 95 restantes são todos datados deste ano, fato que demonstra uma iniciativa por parte dos pesquisadores em conhecer mecanismos que possam contribuir para o entendimento dessa doença e também a sua forma de tratamento.

Essa base classifica os artigos em categorias e/ou áreas de estudo, as dez categorias com maior número de artigos podem ser visualizadas na Figura 4, sendo as de Medicina Geral, Doenças Infecciosas e Virologia as categorias com maior número de artigos recuperados. Outrossim, entre as categorias mostradas, também é possível citar as categorias Biologia Computacional Matemática, Inteligência Artificial de Ciência Computacional e Aplicações Interdisciplinares de Ciência Computacional, apresentando menor número de artigos, porém, isso evidencia a interdisciplinaridade nas pesquisas em temas relacionados à saúde pública.

Figura 4 - Categorias de estudo com maior número de artigos recuperados na Web of Science

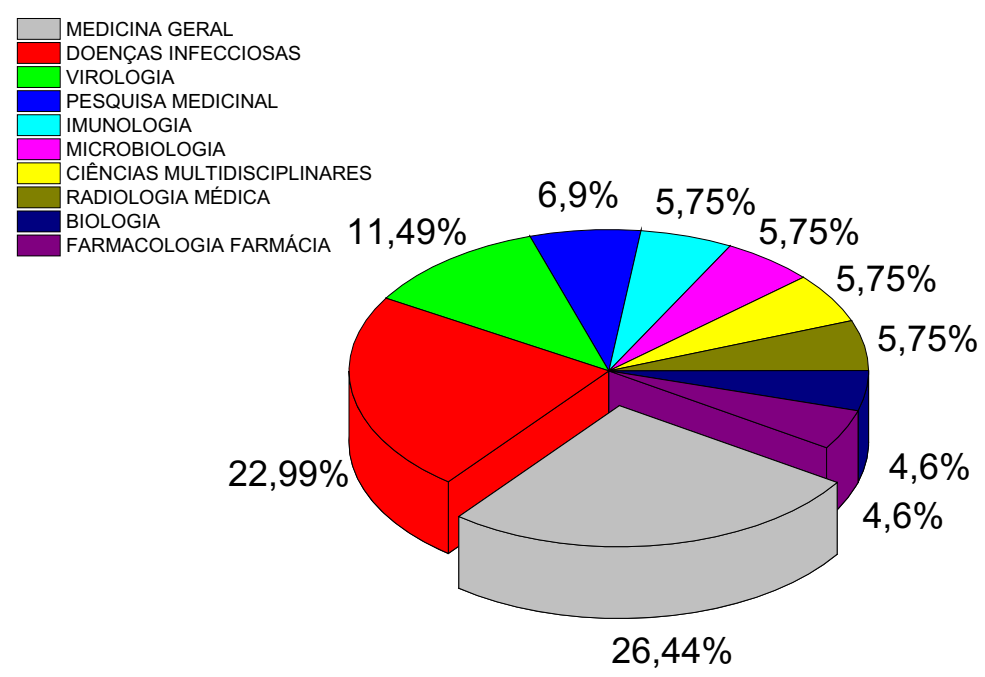

Fonte: Elaborada pelos autores deste artigo (2020) 
Quanto aos países com mais publicações, um destaque pode ser dado à China, pois o país está na primeira posição, com aproximadamente $50 \%$ dos artigos recuperados na base pesquisada, exibindo um resultado esperado, dado o surgimento da COVID-19 ter ocorrido na província de Wuhan, na China, em dezembro de 2019 (HAN et al., 2020; PEERI et al., 2020). Os 10 países com mais publicações para esses descritores estão dispostos na Figura 5. Destaque deve ser dado ao Brasil, uma vez que o país figura na nona posição com três artigos publicados.

Figura 5 - Países com maior número de artigos recuperados na Web of Science (até 30 de março de 2020)

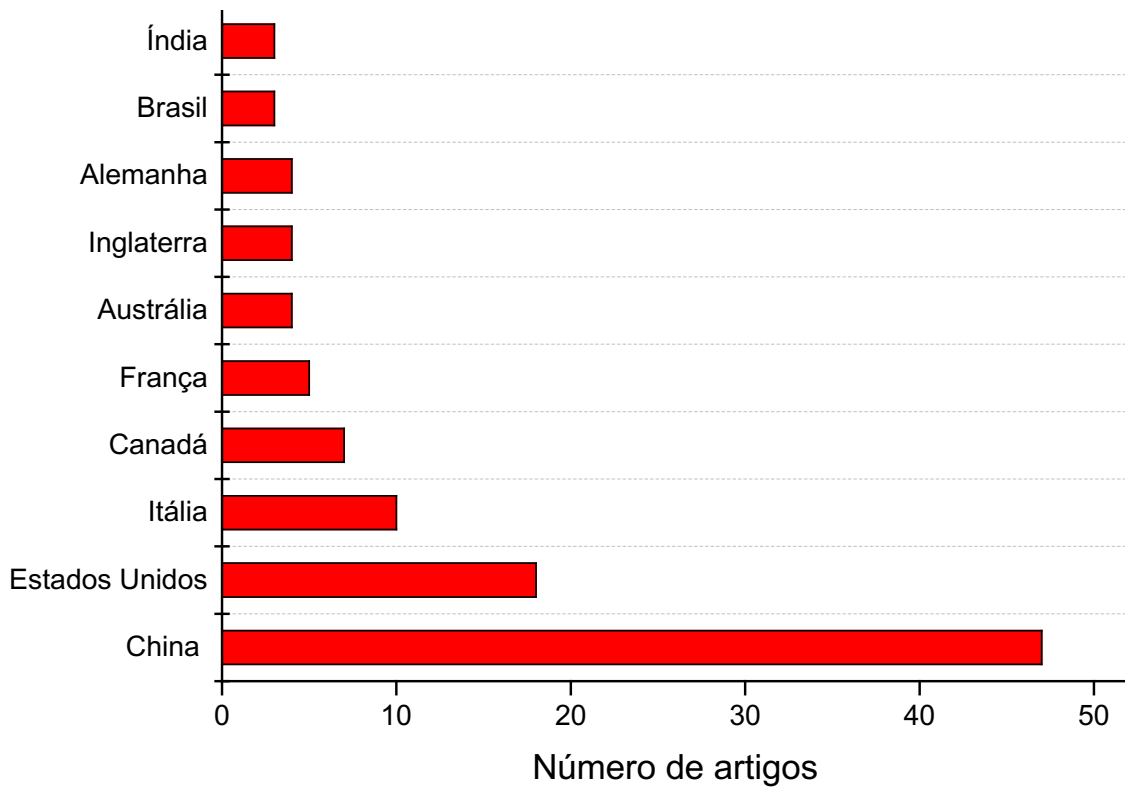

Fonte: Elaborada pelos autores deste artigo (2020)

$\mathrm{Na}$ base de dados do Scopus para esse mesmo conjunto de descritores, a quantidade de artigos recuperados foi maior, cerca de 300, resultado esperado dada a maior abrangência dessa base. Dos 296 artigos recuperados, apenas um é datado do ano de 2019 e os outros 295 foram todos publicados no primeiro trimestre de 2020, reiterando a necessidade de conhecimento dessa doença e de seu tratamento.

Nessa base também se analisou as principais categorias de estudo e os principais países detentores dos estudos publicados. Entre as áreas de estudo, destacaram-se Medicina, Imunologia, Bioquímica e também Ciências Sociais como as categorias com maior número de artigos recuperados. Já a China, os Estados Unidos e a Itália se apresentam no ranking dos países com mais artigos publicados, este último devido ao elevado número de vítimas, sendo 101.739 infectados e 11.591 mortos em 31 de março de 2020 (WHO, 2020). Esses dados estão apresentados nas Figuras 6 e 7. 
Figura 6 - Áreas de estudo com maior número de artigos recuperados no Scopus

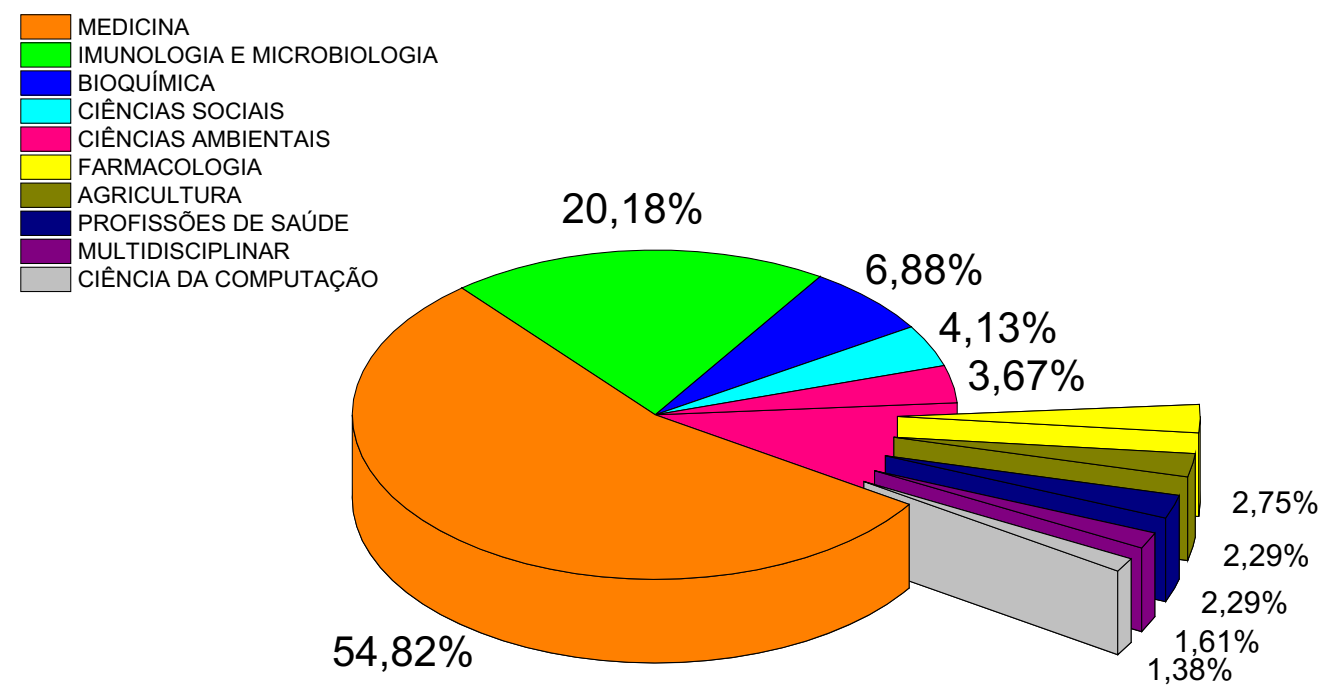

Fonte: Elaborada pelos autores deste artigo (2020)

Figura 7 - Países com maior número de artigos recuperados no Scopus

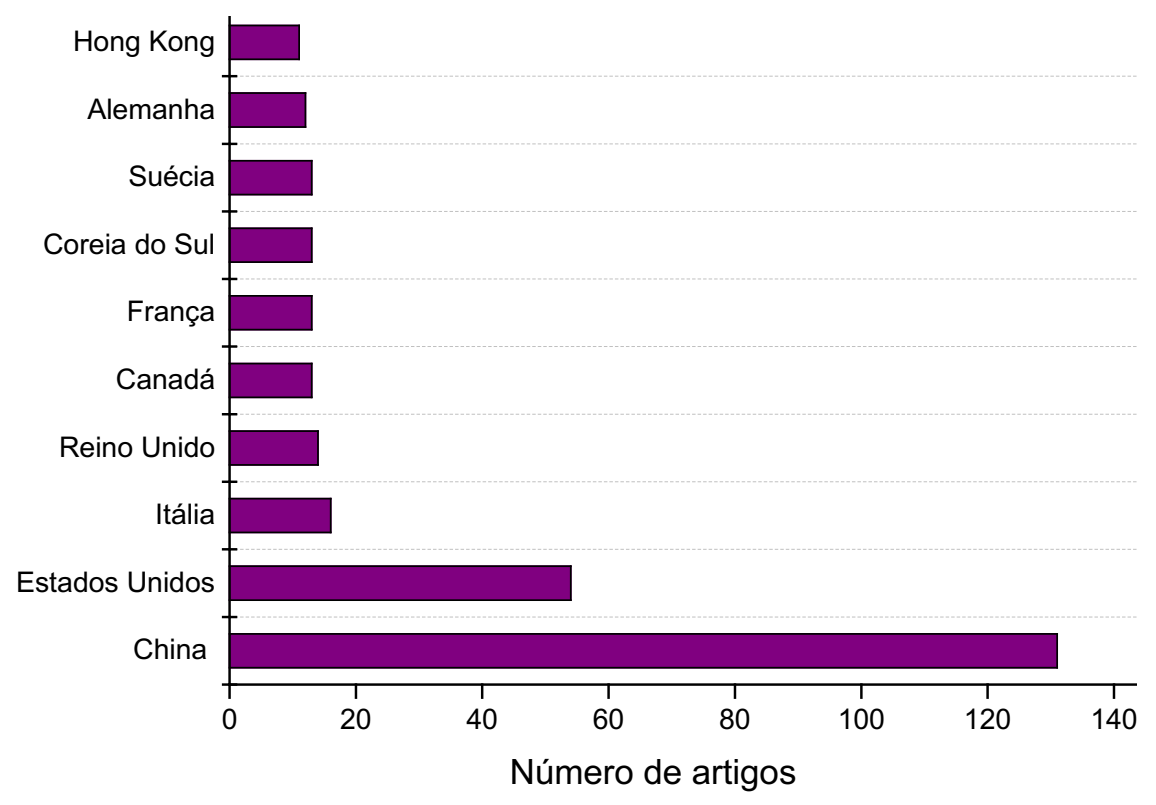

Fonte: Elaborada pelos autores deste artigo (2020)

Os resultados recuperados nas bases de dados para o grupo de descritores mais específicos, o qual inclui os termos "pharmaceutic* OR drug*", também foram analisados. A base Science Direct foi a que apresentou mais artigos científicos relacionados a fármacos no contexto da COVID-19, com 23 registros, seguida da base Scopus, com 21 registros. A base Web of Science recuperou 4 artigos. Todos os artigos datam de 2020.

Os 23 artigos recuperados na base Science Direct foram verificados. Dos 23 registros encontrados, 16 abordavam efetivamente o tema de interesse. A China lidera essa publicação de artigos com nove registros, seguida dos EUA e da Índia, ambos com dois registros. Itália, França 
e Egito colaboram com um artigo cada. A Figura 8 apresenta essa distribuição de artigos por país, em percentual.

Figura 8 - Distribuição por país dos artigos analisados, recuperados na base de dados Science Direct, referentes a fármacos no contexto da COVID-19
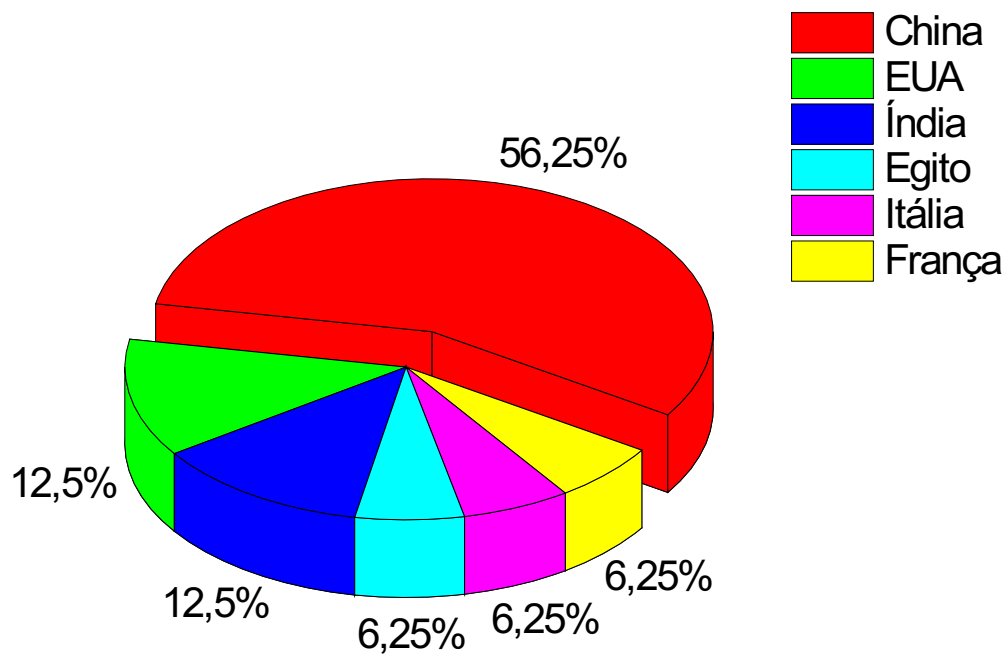

Fonte: Elaborada pelos autores deste artigo (2020)

Ainda acerca dos artigos recuperados na base Science Direct, dos 16 registros analisados, 13 tratavam de artigos de revisão da literatura. Esses documentos trazem um quadro generalizado de informações relativas à atual pandemia da COVID-19, incluindo informações a respeito dos medicamentos com potencial ação terapêutica no tratamento de pacientes acometidos pelo novo Coronavírus. No presente artigo, apenas os fármacos antivirais foram incluídos no levantamento feito e nas análises realizadas.

Os antivirais Cloroquina (GRUPTA; MISRA, 2020; LI, H. et al., 2020; SHING et al., 2020; TOURET; LAMBALLERIE, 2020; ROTHAN; BYRAREDDY, 2020; WANG et al., 2020; ZHANG et al., 2020), Hidroxicloroquina (FAVALLI et al., 2020; GRUPTA; MISRA, 2020; SHING et al., 2020; ZHANG et al., 2020), Remdesivir (AMIRIAN; LEVY, 2020; ELFIKY, 2020; FAVALLI et al., 2020; HAN et al., 2020; LI, H. et al., 2020; LI, X. et al., 2020; SHEREEN et al., 2020; WANG et al., 2020; ZHAI et al., 2020), Ribavirin (ELFIKY, 2020; LI, H. et al., 2020; LI, X. et al., 2020; SHEREEN et al., 2020; ZHAI et al., 2020) e a combinação Lopinavir/Ritonavir (FAVALLI et al., 2020; HAN et al., 2020; LI, H. et al., 2020; LI, X. et al., 2020; WANG et al., 2020; ZHAI et al., 2020) são os fármacos mais apontados na literatura avaliada. As estruturas químicas desses medicamentos são apresentadas no Quadro 2. 
Quadro 2 - Fármacos antivirais mais apontados na literatura consultada na base de dados Science Direct e suas respectivas estruturas químicas

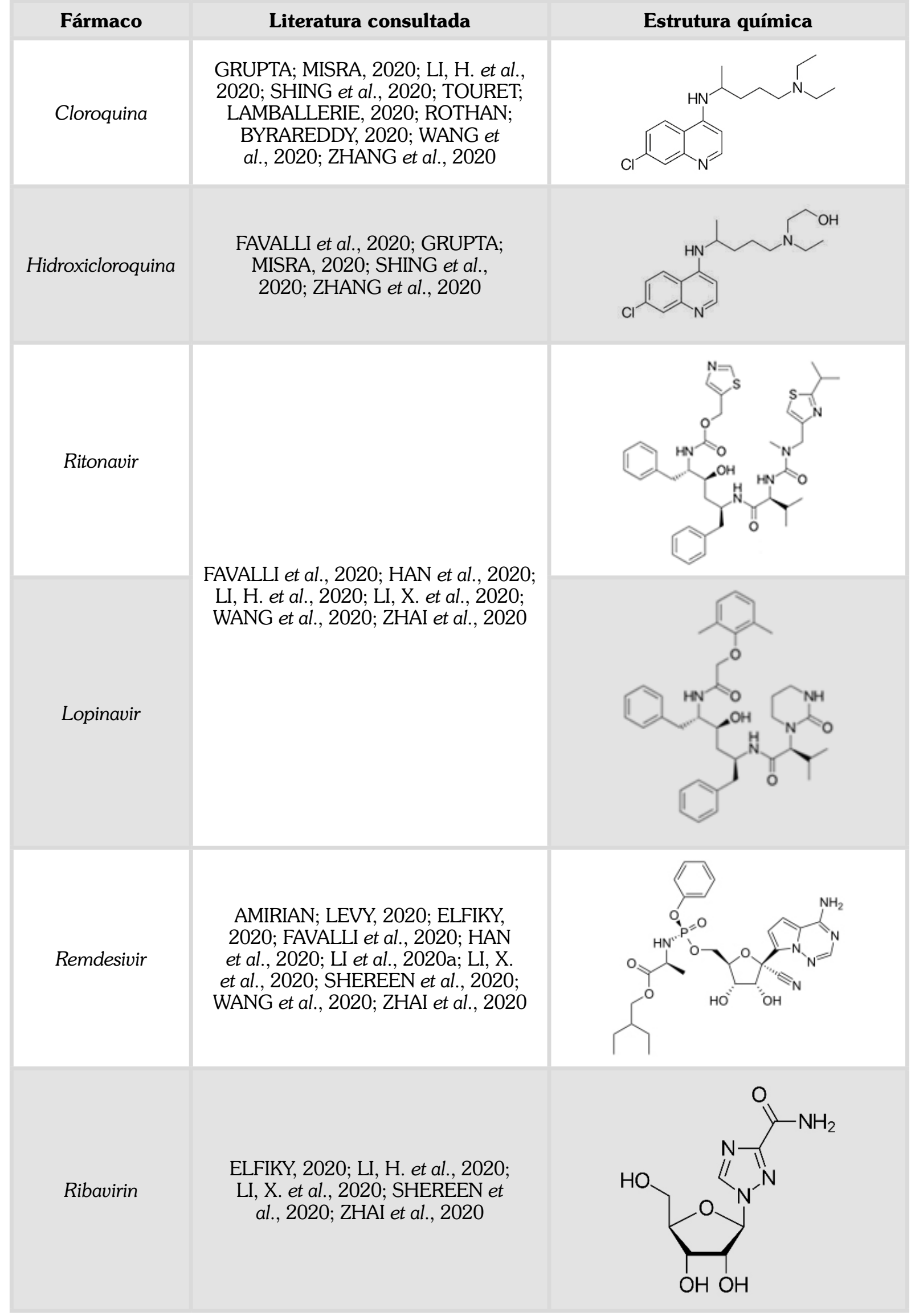

Fonte: Elaborado pelos autores deste artigo (2020) 
A Cloroquina é um fármaco amplamente utilizado no tratamento da malária e de doenças autoimunes (LI, H. et al., 2020). Segundo o levantamento realizado por Grupta e Misra (2020), a cloroquina apresenta boa eficácia para os testes in vitro, e a China obteve também boa eficácia em pacientes com COVID-19. Um pequeno estudo realizado com 36 pacientes na França exibiu bons resultados com o uso da Hidroxicloroquina (um análogo da cloroquina), principalmente acerca do seu uso combinado com Azitromocina. Ainda, de acordo com os autores, em virtude da boa tolerância da Hidroxicloroquina e de seu baixo custo, ela pode ser oferecida como uma espécie de tratamento experimental (medicamento ainda não aprovado para tratar essa enfermidade) para pacientes com quadro moderado a severo de COVID-19.

A combinação dos medicamentos anti-HIV (Vírus da Imunodeficiência Humana) Lopinavir e Ritonavir também tem sido recomendada para o tratamento de pacientes com o novo Coronavírus, uma vez que tais medicamentos já foram efetivos para SARS-Cov e MERS-Cov (HAN et al., 2020).

Um dos artigos de pesquisa encontrado relatava o estudo desenvolvido por Cai et al. (2020) na China, no qual os efeitos do fármaco Favipiravir foram analisados em comparação à combinação Lopinavir/Ritonavir no tratamento de pacientes acometidos pela COVID-19. Para os dois tratamentos, foi acrescentado o uso de Interferon- $\alpha$ por inalação de aerossol. Nesse estudo de controle aberto e não randomizado, o Favipiravir apresentou efeitos de tratamento significativamente melhores.

Uma outra pesquisa desenvolvida por Elfiky (2020) no Egito, mediante estudo de acoplamento molecular, sugere que os fármacos Ribavirin, Remdesivir, Sofodbuvir, Galidesivir e Tenofovir são eficazes contra o novo Coronavírus.

O Remdesivir foi originalmente desenvolvido para tratar a infecção pelo vírus Ebola (AMIRIAN; LEVY, 2020) e recentemente indicado como um promissor fármaco antiviral para um amplo espectro de vírus RNA (WANG et al., 2020). Um estudo mostrou que o medicamento pode inibir a infecção por COVID-19 in vitro e seu uso foi eficaz no tratamento do primeiro caso nos Estados Unidos; um estudo clínico de fase 3 está em andamento em Wuhan e um de fase 2 foi realizado pelo Centro Médico da Universidade de Nebraska (HAN et al., 2020; WANG et al., 2020; ZHAI et al., 2020).

O Ribavirin é uma medicação com amplo espectro antiviral, podendo impedir a replicação dos vírus RNA e DNA. Foi amplamente utilizado no tratamento de pacientes durante o surto de SARS em Hong Kong e, por isso, é indicado como uma possível opção de tratamento para a COVID-19 (LI, H. et al., 2020).

O Arbidol, de acordo com Han et al. (2020), apresenta um amplo espectro de ação antiviral contra vírus respiratórios, e notícias recentes relataram que esse fármaco pode inibir o novo Coronavírus in vitro. Há, além disso, registro de um ensaio clínico de fase 4 para a nova pneumonia desencadeada pela COVID-19 (NCT04246242).

De acordo com Shereen et al. (2020), os antivirais Nafamostat, Nitazoxanida, Ribavirin, Penciclovir, Favipiravir, Ritonavir, AAK1, Baricitinib e Arbidol exibiram resultados moderados quando avaliados contra a infecção por COVID-19 em testes clínicos em pacientes e in vitro.

O Interferon- $\alpha$ é apontado por Li, H. et al. (2020) como um potencial medicamento no tratamento da COVID-19 por apresentar ação antiviral, interferindo na replicação do vírus e promovendo respostas imunes inatas e adaptativas à infecção. A indicação é baseada em expe- 
riências in vitro que mostraram que o fármaco é capaz de inibir a replicação do SARS-CoV e, em um ensaio clínico-piloto, demonstrou o seu benefício terapêutico em pacientes com SARS.

Segundo a literatura, apesar das várias opções terapêuticas experimentadas em pacientes com COVID-19, ainda não há um tratamento específico. Assim, o atual protocolo de tratamento de pacientes com COVID-19 é principalmente sintomático, incluindo também repouso, manutenção de boas condições corporais, monitoramento de sinais vitais e uso de antibióticos de amplo espectro para tratar infecções bacterianas secundárias (HAN et al., 2020; LI, H. et al., 2020; LI, X. et al., 2020.; WANG et al., 2020; ZHAI et al., 2020).

$\mathrm{Li}$, J. et al. (2020) apontam que o desenvolvimento de novos medicamentos é um processo muito longo e, em uma epidemia tão repentina, é impraticável pelos princípios tradicionais. $\mathrm{O}$ que os cientistas estão fazendo é uma triagem sistemática e em larga escala dos fármacos existentes para verificar se apresentam atividade contra o novo Coronavírus.

É importante ressaltar que, apesar dos bons resultados para os testes de alguns fármacos in vitro, é necessário ter cautela quanto ao uso dos medicamentos aqui listados, uma vez que pouquíssimos ensaios clínicos foram realizados e, ainda assim, de forma não randomizada, situação não ideal adotada no momento devido à urgência da situação. Portanto, é indispensável a realização de mais testes para que se verifique a potencialidade terapêtica e os efeitos colaterais relacionados aos antivirais apontados pela literatura. Ademais, toda adoção de protocolos de uso desses medicamentos passa pela rígida validação das autoridades de saúde, além disso, esses protocolos devem ser respeitados sumariamente, como forma de proteção da saúde pública. Destaque-se ainda a importância de análise desses estudos pelos comitês de ética em pesquisa, de forma a garantir a utilização de preceitos científicos e morais compatíveis com o pensamento contemporâneo.

\section{Considerações Finais}

A pandemia da COVID-19 já é um sério problema de saúde mundial. Cientistas de diversas áreas têm se dedicado ao estudo do novo Coronavírus e ao desenvolvimento de estratégias para prevenção, triagem e tratamento de pacientes infectados, o que reflete o número considerável de 296 artigos (na base Scopus) publicados acerca do tema, após apenas três meses da primeira infecção. Número que provavelmente será muito mais elevado ao longo de cada mês, principalmente considerando o montante de publicações observado a partir de 1951, de quando datam os primeiros artigos, e os picos verificados devido ao surgimento da SARS-CoV, em 2002, e da MERS-CoV, em 2012.

Apesar do período legal de sigilo relacionado ao depósito de patentes, considerando o surgimento da COVID-19 em dezembro de 2019, já está disponível uma patente relacionada a um preparado da medicina tradicional chinesa para o tratamento da doença. Analisando o número alto de patentes relacionadas aos coronavírus, apontado até o presente momento (2.977 no software do Questel Orbit), e os picos observados devido ao surgimento das SARS-CoV (2002) e da MERS-CoV (2012), há real perspectiva de crescimento acentuado nos próximos anos, à medida que o período de sigilo de cada patente seja findado, particularmente devido ao caráter pandêmico atribuído à COVID-19. Considerando a importância dessa doença, se comparada às 
de 2002 e 2012, espera-se já, para 2020 e 2021, algumas centenas, talvez milhares, de depósitos, particularmente com prioridade inicial nos países mais atingidos, em especial China e EUA.

Uma das estratégias adotadas pelos pesquisadores frente à urgente busca de medicamentos para o tratamento de pacientes acometidos pela COVID-19 consiste em testes (in vitro e in vivo) de fármacos com possíveis atividades antivirais, bem como fármacos antivirais com conhecida ação para outros vírus. Nesse contexto, mais de 20 fármacos estão sendo verificados, de forma isolada e em combinações, em diversas partes do mundo. Alguns desses, inclusive, já foram submetidos a pequenos testes realizados com pacientes acometidos pela infecção, no entanto, uma triagem maior é necessária para definição da ação terapêutica e a indicação desses medicamentos para o protocolo de tratamento. Um dos elementos fundamentais para adoção desses protocolos de tratamento é a densidade estatística dos experimentos, o que até o momento é bastante limitado na literatura, mas certamente será maximizado com os estudos cooperativos, inclusive entre grupos internacionais, já em desenvolvimento, além das dimensões de acometimento da doença por pessoas de todo o planeta.

\section{Referências}

AMIRIAN, E. Susan; LEVY, Julie K. Current knowledge about the antivirals remdesivir (GS-5734) and GS-441524 as therapeutic options for coronaviruses. One Health, [S.l.], p. 100128, 2020.

CAI, Qingxian et al. Experimental treatment with favipiravir for COVID-19: an open-label control study. Engineering, [S.l.], 2020.

CUI, J.; LI, F.; SHI, Z.L. Shi. Origin and evolution of pathogenic coronaviruses. Nat. Rev. Microbiol., [S.l.], n. 17, p. 181-192, 2019.

DERWENT. Base de dados on-line. [2020]. Disponível em: http://apps-webofknowledge.ez9. periodicos.capes.gov.br/DIIDW_GeneralSearch_input.do?product=DIIDW\&SID=7Ar5bU9PQIZ4iN7 1VS3\&search_mode $=$ GeneralSearch. Acesso em: 30 mar. 2020.

DROSTEN, Christian et al. Identification of a novel coronavirus in patients with severe acute respiratory syndrome. New England Journal of Medicine, [S.l.], v. 348, n. 20, p. 1.967-1.976, 2003.

ELFIKY, Abdo A. Ribavirin, Remdesivir, Sofosbuvir, Galidesivir, and Tenofovir against SARS-CoV-2 RNA dependent RNA polymerase (RdRp): A molecular docking study. Life Sciences, [S.l.], p. $117592,2020$.

ESPACENET. Base de dados on-line. [2020]. Disponível em: https://worldwide.espacenet.com/. Acesso em: 30 mar. 2020.

FAVALLI, Ennio Giulio et al. COVID-19 infection and rheumatoid arthritis: Faraway, so close! Autoimmunity Reviews, [S.l.], p. 102523, 2020.

FOSTER, S.; TYLER, V. E. Tyler's Honest Herbal, 4th ed. Binghamton, NY: Haworth Herbal Press, 1999, 442 p.

GILBERT, Marius et al. Preparedness and vulnerability of African countries against importations of COVID-19: a modelling study. The Lancet, [S.I.], v. 395, n. 10.227, p. 871-877, 2020. 
GUPTA, Ritesh; MISRA, Anoop. Contentious issues and evolving concepts in the clinical presentation and management of patients with COVID-19 infectionwith reference to use of therapeutic and other drugs used in Co-morbid diseases (Hypertension, diabetes etc.). Diabetes \& Metabolic Syndrome: Clinical Research \& Reviews, [S.l.], 2020.

HAN, Qingmei et al. Coronavirus 2019-nCoV: A brief perspective from the front line. Journal of Infection, [S.I.], v. 80, n. 4, p. 373-377, 2020.

INPI - INSTITUTO NACIONAL DA PROPRIEDADE INDUSTRIAL. Base de dados on-line. [2020]. Disponível em: https://gru.inpi.gov.br/pePI/jsp/patentes/PatenteSearchAvancado.jsp. Acesso em: 30 mar. 2020.

INPI - INSTITUTO NACIONAL DA PROPRIEDADE INDUSTRIAL. Classificação de patentes. 2020. Disponível em: http://www.inpi.gov.br/menu-servicos/patente/classificacao-de-patentes. Acesso em: 30 mar. 2020.

KHACHFE, Hussein H. et al. An epidemiological study on COVID-19: a rapidly spreading disease. Cureus, [S.I.], v. 12, n. 3, 2020.

KSIAZEK, Thomas G. et al. A novel coronavirus associated with severe acute respiratory syndrome. New England Journal of Medicine, [S.l.], v. 348, n. 20, p. 1.953-1.966, 2003.

LI, Heng et al. Coronavirus disease 2019 (COVID-19): current status and future perspective. International Journal of Antimicrobial Agents, [S.l.], p. 105951, 2020.

LI, Jin-Yan et al. The epidemic of 2019-novel-coronavirus (2019-nCoV) pneumonia and insights for emerging infectious diseases in the future. Microbes and Infection, [S.I.], v. 22, n. 2, p. 80-85, 2020.

LI, Xiaowei et al. Molecular immune pathogenesis and diagnosis of COVID-19. Journal of Pharmaceutical Analysis, [S.1.], 2020.

PEERI, Noah C. et al. The SARS, MERS and novel coronavirus (COVID-19) epidemics, the newest and biggest global health threats: what lessons have we learned? International Journal of Epidemiology, [S.I.], 2020.

QUESTEL ORBIT. Base de dados on-line. [2020]. Disponível em: https://www.orbit.com. Acesso em: 30 mar. 2020.

ROTHAN, Hussin A.; BYRAREDDY, Siddappa N. The epidemiology and pathogenesis of coronavirus disease (COVID-19) outbreak. Journal of Autoimmunity, [S.l.], p. 102433, 2020.

SCIENCE DIRECT. Base de dados on-line. [2020]. Disponível em: https://www.sciencedirect.com/. Acesso em: 30 mar. 2020.

SCIENTIFIC ELECTRONIC LIBRARY ONLINE (SciELO). Base de dados on-line. [2020]. Disponível em: http://www.scielo.org/php/index.php. Acesso em: 30 mar. 2020.

SCOPUS. Base de dados on-line. [2020]. Disponível em: https://www.scopus.com/home.uri. Acesso em: 30 mar. 2020.

SHEREEN, Muhammad Adnan et al. COVID-19 infection: origin, transmission, and characteristics of human coronaviruses. Journal of Advanced Research, [S.l.], 2020.

SIGMA-ALDRICH. Catálogo de produtos Químicos finos. [2020]. Disponível em: https://www. sigmaaldrich.com/catalog/product/aldrich/134910?lang=pt\&region=BR. Acesso em: 31 mar. 2020. 
SINGH, Awadhesh Kumar et al. Chloroquine and hydroxychloroquine in the treatment of COVID-19 with or without diabetes: A systematic search and a narrative review with a special reference to India and other developing countries. Diabetes \& Metabolic Syndrome: Clinical Research \& Reviews, [S.1.], 2020.

TOURET, Franck; DE LAMBALLERIE, Xavier. Of chloroquine and COVID-19. Antiviral Research, [S.l.], p. 104762, 2020.

UNLUGENC, Hakki et al. Rapid fluid administration and the incidence of hypotension induced by spinal anesthesia and ephedrine requirement: the effect of crystalloid versus colloid coloading. Middle East J Anaesthesiol, [S.l.], v. 23, n. 3, p. 273-81, 2015.

WANG, Li-sheng et al. A review of the 2019 Novel Coronavirus (COVID-19) based on current evidence. International Journal of Antimicrobial Agents, [S.l.], p. 105948, 2020.

WEB OF SICENCE. Base de dados on-line. [2020]. Disponível em: http://apps-webofknowledge. ez9.periodicos.capes.gov.br/WOS_GeneralSearch_input.do?product $=$ WOS\&search_mode $=$ General Search\&SID=7Ar5bU9PQIZ4iN71̄VS3\&preferencesSaved =. Acesso em: 30 mar. 2020.

WEISS, Susan R.; LEIBOWITZ, Julian L. Coronavirus pathogenesis. In: WEISS, Susan R.; LEIBOWITZ, Julian L. Advances in Virus Research. [S.I.]: Academic Press, 2011. p. 85-164.

WHO - WORLD HEALTH ORGANIZATION. [2020]. Disponível em: https://www.who.int/docs/ default-source/coronaviruse/situation-reports/20200331-sitrep-71-covid-19.pdf?sfursn=4360e92b_8. Acesso em: 31 mar. 2020.

WOO, Patrick Cy et al. Discovery of seven novel Mammalian and avian coronaviruses in the genus deltacoronavirus supports bat coronaviruses as the gene source of alphacoronavirus and betacoronavirus and avian coronaviruses as the gene source of gammacoronavirus and deltacoronavirus. Journal of Virology, [S.l.], v. 86, n. 7, p. 3.995-4.008, 2012.

ZHAI, Pan et al. The epidemiology, diagnosis and treatment of COVID-19. International Journal of Antimicrobial Agents, [S.l.], p. 105955, 2020.

ZHANG, Wen et al. The use of anti-inflammatory drugs in the treatment of people with severe coronavirus disease 2019 (COVID-19): The experience of clinical immunologists from China. Clinical Immunology, [S.I.], p. 108393, 2020.

ZHU, Na et al. A novel coronavirus from patients with pneumonia in China, 2019. New England Journal of Medicine, [S.l.], 2020.

\section{Sobre os Autores}

\section{Williams Raphael de Souza Morais}

E-mail: williamsraphael745@gmail.com

Mestre em Ciências, subárea Físico-Química pela UFAL, (2018).

Endereço profissional: Universidade Federal de Alagoas, Instituto de Química e Biotecnologia, Laboratório de Eletroquímica Aplicada, Campus A. C. Simões, Avenida Lourival Melo Mota, s/n, Tabuleiro dos Martins, Maceió, AL. CEP: 57072-900. 


\section{Nathalia Marcelino Pereira Queiroz}

E-mail: nathaliampereira@gmail.com

Doutora em Ciências dos Materiais pela UFAL, (2019).

Endereço profissional: Universidade Federal de Alagoas, Instituto de Química e Biotecnologia, Laboratório de Eletroquímica Aplicada, Campus A. C. Simões, Avenida Lourival Melo Mota, s/n, Tabuleiro dos Martins, Maceió, AL. CEP: 57072-900.

\section{Jaceguai Soares da Silva}

E-mail: jaceguai.silva@ifap.edu.br

Doutor em Ciências, subárea Físico-Química pela UFAL, (2018).

Endereço profissional: Instituto Federal de Educação, Ciência e Tecnologia do Amapá, Campus Laranjal do Jari, Rua Nilo Peçanha, n. 1263, Cajari, Laranjal do Jari, AP. CEP: 68920-000.

\section{Adriana Santos Ribeiro}

E-mail: drisribeiro@gmail.com

Doutora em Química pela UNICAMP, (2003).

Endereço profissional: Universidade Federal de Alagoas, Instituto de Química e Biotecnologia, Laboratório de Eletroquímica Aplicada, Campus A. C. Simões, Avenida Lourival Melo Mota, s/n, Tabuleiro dos Martins, Maceió, AL. CEP: 57072-900.

\section{Joselado Tonholo}

E-mail: tonholo@gmail.com

Doutor em Química, subárea Físico-Química pela USP, (1997).

Endereço profissional: Universidade Federal de Alagoas, Instituto de Química e Biotecnologia, Laboratório de Eletroquímica Aplicada, Campus A. C. Simões, Avenida Lourival Melo Mota, s/n, Tabuleiro dos Martins, Maceió, AL. CEP: 57072-900. 